\title{
O ESPLENDOR ILUSÓRIO EM UM DISCURSO DERRAMADO
}

Professora da Universidade de Montes Claros - UNIMONTES. Doutora LIteraturas de Língua Portuguesa. Bolsista FAPEMIG.
Alexsandra Loiola Sarmento

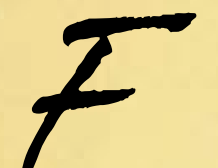

Resumo

ste artigo busca analisar o jogo de linguagem empregado no discurso do narrador do romance Leite Derramado, de Chico Buarque, com apoio nos textos "A negativa", de Freud, e "Sobre verdade e mentira no sentido extramoral", de Nietzsche. O objetivo da leitura consiste em mostrar de que maneira a verdade e a mentira, já tematizadas pelo artista no poema-canção "Verdadeira embolada", encontram-se entrelaçadas nessa obra literária. O que suscita a reflexão sobre como as astúcias da palavra foram utilizadas para expor e desmascarar um figurão brasileiro a partir de sua confissão involuntária.

Palavras-chave: Leite Derramado. Chico Buarque. Esplendor Ilusório. Nietzsche. Freud.

Leite Derramado traz como narrador-personagem Eulálio d'Assumpção, já centenário, num hospital público, em estado terminal. $\mathrm{O}$ sentido de decadência desponta no enredo: o narrador-personagem, senhor de posses, nome de linhagem, com o passar do tempo, chega à ruína material e sente-se próximo à indigência. Daí a importância da narrativa como meio de afirmação de si mesmo. Assim, ao tratar da sua constituição familiar, vangloria-se de seus ancestrais, por considerar-se descendente de nobres portugueses, de senhores de escravos, de um barão do Império, além de filho de senador da República. Exalta-se por acreditar pertencer a uma família nobre, ilustrada. $\mathrm{Na}$ história pretensiosa que nos é contada, pode se perceber uma expressão ilusória da realidade como meio de proteção e conservação da própria identidade, como bem nos esclarece Nietzsche: 
Como meio para conservação do indivíduo, o intelecto desenrola suas principais forças na dissimulação; pois esta constitui o meio pelo qual os indivíduos mais fracos, menos vigorosos, conservam-se, como aqueles aos quais é denegado empreender uma luta pela existência com chifres e presas afiadas. No homem, essa arte da dissimulação atinge seu cume: aqui, o engano, o adular, mentir e enganar, o falar pelas costas, o representar, o viverem esplendor consentido, o mascaramento, a convenção acobertadora, o fazer drama diante dos outros e de si mesmo, numa palavra o constante saracotear em torno da chama única da vaidade, constitui a tal ponto a regra e a lei. (NIETZSCHE, 2007, p. 27-28).

Assim, descontente com as verdades desagradáveis, o homem troca o vazio da vida por ilusões. No entanto, a mesma linguagem expressiva da ilusão é capaz também de deixar à mostra nuances de uma dada realidade submersa. Por entre o discurso proferido por Eulálio d'Assumpção em torno de sua genealogia, escorre um contra discurso a desmentir a pretensa história de homem bem nascido. A pureza de sua própria origem, dos antepassados, de parentes e dos membros que compõem o círculo social em que convive é relativizada. Em meio à versão orgulhosa de pertencer a uma elite nobre, pela origem e pelo poder de mando, o narrador, talvez, sem perceber, emite fatos e aspectos que, como evidências capazes de falar por si mesmas, desmentem a noção de pureza de origem, de classe e de etnia.

Saiba o doutor que meu pai foi republicano de primeira hora, íntimo de presidentes, sua morte brutal foi divulgada até em jornais da Europa, onde desfrutava imenso prestígio e intermediava café. Tinha negócios com armeiros da França, amigos graúdos em Paris, e na virada do século, ainda muito jovem, fez sociedade com empresários ingleses. Espírito prático, foi parceiro dos ingleses na Manaus Harbour, e não na aventura africana de seu pai, igualmente vítima de ciúmes e maledicências. Fique sabendo que meu avô nasceu muito rico, não iria macular seu nome por se locupletar com dinheiro público. Mas com o fim do Império, teve de buscar asilo em Londres, onde morreu amargurado. (BUARQUE, 2009, p. 52).

Ao chamar a atenção sobre sua própria pessoa, informações implícitas que desqualificam os seus antepassados vêm à tona e confrontam as intenções de honrarias à família. $\mathrm{Na}$ referência elogiosa ao pai, subtraem-se informações um tanto desagradáveis do avô, em sua aventura africana, quando foi 
"vítima de ciúmes e maledicências" e teve que "buscar asilo em Londres, onde morreu amargurado.". O elogio vai, assim, se transformando numa espécie de denúncia, da qual se podem colher pistas que condenam o comportamento de seus ascendentes. No discurso de enaltecimento do pai identificase um tipo especial de construção de linguagem, em que o negar constitui uma afirmação. A referência elogiosa perde sua força enaltecedora na estrutura comparativa do pai com o avô: "Espírito prático, foi parceiro dos ingleses na Manaus Harbour, e não na aventura africana de seu pai, igualmente vítima de ciúmes e maledicências." Se, por um lado, procura-se exaltar, pela comparação diferenciadora, "não na aventura africana do seu pai", por outro lado, a comparação não deixa de rebaixar a figura paterna. Comparação que nega e afirma. A contraditar a exaltação, o leitor pode questionar, ao ler o excerto, qual seria o motivo de se expor uma defesa ao avô? E pode se verificar que é pela defesa que se denunciam os atos ilícitos: "Fique sabendo que meu avô já nasceu muito rico, não iria macular seu nome por se locupletar com dinheiro público.". Aí se vê que a negação indica as possibilidades da existência do que se procura negar. Ainda mais quando se conhece que fora punido por atos praticados: "Mas com o fim do Império, teve de buscar asilo em Londres, onde morreu amargurado."

Por um processo de transferência de sentido, como é próprio da comparação, que só tem razão de existir a partir de uma igualdade subjacente aos termos, infere-se que o mesmo que acontecera ao avô, nesse processo de linguagem, tenha se passado também ao pai, o senador Eulálio d'Assumpção. Da mesma feita, enquanto o avô pagou pela mácula da corrupção, no exílio amargurado, o senador fora assassinado. Assim, a morte do próprio pai levanta suspeita de prática de corrupção, pois não é certeza que tenha sido morto por crime passional. Maria Violeta, a mãe do narrador, cogita que o marido tenha sido alvo de um crime por negociata política. Motivos que dão mostras da presença de alguma mancha em sua conduta moral. Atente-se para as descrições feitas do senador Assumpção: "Nunca uma nódoa, uma ruga na roupa, meu pai de manhã sai do quarto tão alinhado quanto entrou de noite, e quando menor eu acreditava que ele dormia em pé de feito cavalo." (BUARQUE, 2009, p. 104). Note-se que essa negativa não está dissociada da referência antes feita ao avô, sobre não se beneficiar de dinheiro público, no enunciado: "não iria macular o seu nome em se locupletar com dinheiro público." A semelhança entre os enunciados pode ser percebida pela 
presença de termos que mantêm uma correlação de sentido, o "não" e o "nunca"; a "mácula" e a "nódoa" que transportam um mesmo sentido: a negação da existência de falhas de seus nobres ascendentes.

Observa-se que o discurso vem acompanhado de um contra discurso, negativas que valem como assertivas. Por meio da compreensão das mensagens subliminares, tem-se acesso ao recôndito da linguagem. Segundo Freud, em seu estudo sobre "A negativa", o que é rejeitado, negado, estirpado, dado como falso, mentiroso constitui a própria verdade, o significado latente. Em determinados contextos, o termo negativo pode ser apagado do enunciado podendo ser considerado apenas o conteúdo geral (FREUD, 2006). É desse modo que toda a imagem de manchas antes negada aparece nas mãos sarapintadas da costureira francesa que entrega o vestido ao pai e na pele sardenta da amante. A negação da existência da nódoa é desfeita por completo quando se narra o assassinato do pai, momento em que a nódoa e a mácula são pintadas com cores encarnadas.

[...] vai restar visível uma mancha úmida no colchão, que tratarei de virar como faço toda manhã, deixando para cima o lado das manchas secas. Terei a sensação de que o colchão pesa mais um pouco, a cada dia e imaginarei que na palha dentro dele, se impregna a pasta de meus sonhos e atos solitários. E pensarei que, se eu tivesse virado o corpo do meu pai na garçonnière, ele pesaria igual ao colchão e exalaria o mesmo cheiro. Sempre me lembrarei do meu pai de bruços no tapete ensaguentado, e de como o delegado me impediu de tocar o corpo. Ele não precisava me apertar o braço, eu só não queria deixar meu pai daquele jeito, com a boca aberta no tapete. E queria entender por onde entraram tantas balas, porque parecia que todo o sangue dele tinha saído pela boca, aquela grande úlcera. (BUARQUE, 2009, p. 70).

O sangue escorrido da boca do senador mancha o tapete. A morte do senador por assassinato é motivo de discussão sobre sua idoneidade. "E pelos cochichos compreendi que o nome do meu pai, notável da República, caíra de um jeito grosseiro na boca do povo, Assunção, o assassino? Assunção, o corno?" (BUARQUE, 2009, p. 57). Veja-se que nesse enunciado, o nome do pai aparece decaído em Assunção, sem o significante " $p$ ". O texto leva a compreender que o motivo do crime estaria ligado a um ato de traição. Enquanto Maria Violeta, a mãe do narrador, associa o crime a uma traição política, Eulálio 
d'Assumpção, parece querer entender tratar-se de um crime passional. O narrador parece reagir tal como fizera em sua meninice: "vai restar visível uma mancha úmida no colchão, que tratarei de virar como faço toda manhã." (BUARQUE, 2009, p. 57). Essa atitude mimetiza o ato de negar, escamotear a verdade considerada desqualificante, corresponde à ação de rejeitar a realidade indesejada. Conforme Nietzsche, a verdade que o homem anseia é uma verdade limitada.

Ele quer as consequências agradáveis da verdade, que conservam a vida; frente ao puro conhecimento sem consequências ele é indiferente, frente as verdades possivelmente destruidoras ele se indispõe com hostilidade, inclusive. (NIETZSCHE, 2007, p. 30)

Quanto à Matilde, mulher do narrador, diz-se que o seu pai era um deputado que mantinha relações extraconjugais com a "gente do Norte." No texto, a região norte do país é referenciada em tom pejorativo, como se fosse uma região que possuísse uma população primitiva, por ser composta de pessoas mestiças, de condição social humilde, portadora de uma cultura inferiorizada, diferente da considerada com alto desenvolvimento e nível cultural. Assim, uma das personagens enuncia: "Deve ter outras, ela disse, o traidor deve ter outras por lá. E depois de um suspiro acrescentou essa gente do Norte.” (BUARQUE, 2009, p.73). Há, na reprodução da fala, uma classificação de pessoas, entre os que pertencem aos desenvolvidos, civilizados, bem-nascidos, aos puros e, no dizer de Roberto Damatta, "as gentinhas", "a gentalha", "numa palavra, aos impuros em geral.” (DAMATTA, 1997, p. 204).

Do mesmo modo, o genro de Eulálio d'Assumpção, Amerigo Palumba, de quem se orgulhava por representar grupos financeiros internacionais e considerava interessante por apresentar-se bem vestido - "O lenço de seda, a abotoadura de brilhantes, a pérola na gravata, tinha lá sua graça o estilo"o surpreende e decepciona quando abandona a filha, levando embora todo o dinheiro adquirido com a venda dos imóveis herdados (BUARQUE, 2009, p. 37). Além disso, a imagem de boa aparência e aparato social do genro é contrastada com a informação de que seu pai conseguira enriquecer-se estripando porcos. Tal atividade é vista pelo narrador de forma rebaixadora, como se fosse algo do que se envergonhar, e, portanto, acreditava que o filho "deve ter erguido as mãos para o céu durante a guerra, quando as bandas antifacistas incendiaram seus frigoríficos.” (BUARQUE, 2009, p. 37). 
O alto e o baixo, elevações e descidas, os desníveis sociais dão a perceber as muitas misturas, de tal modo que não é de se espantar que a própria mãe, Maria Violeta, tenha, após a viuvez, se unido a um de seus empregados, o chofer Auguste. Ele estava pronto para servi-la, ocupava uma condição subalterna, porém, era elegante e falava francês. Passou a fazer o papel de marido. Como mostra disso, passa a vestir os pijamas do senador, com suas insígnias, a dividir a cama com Maria Violeta e atendê-la pelo nome do marido, Eulálio d'Assumpção. O comportamento do chofer mimetiza bem o ritual de destronamento da festa carnavalesca, na qual o nobre é travestido em escravo e o escravo ascende à condição de rei, conforme Bakhtin (2010).

Sob essa mesma perspectiva, os vínculos culturais são encontrados em várias passagens da narrativa, de modo a tornar relativo o que, até então, era considerado nobre, culto, elevado, confirmando a cosmovisão carnavalesca da sátira da menipeia no estilo do romance. Assim, até mesmo o francês Jacques Dubosc, representante de uma cultura elevada, - a cultura francesa - demonstra o gosto de tomar batida de limão e de caçar capivaras em meio a índios selvagens. Não é de se espantar, pois, que Eulálio Montenegro d'Assumpção, filho de Senador e neto de Barão, seja flagrado demonstrando "direito de primícias de senhor" com Balbino, colega negro, descendente de escravos: "Eu estava com dezessete anos, talvez dezoito, o certo é que já conhecia mulher, inclusive as francesas. Não tinha, portanto, necessidade daquilo, mas do nada decidi que ia enrabar o Balbino." (BUARQUE, 2009, p. 19). Embora acreditasse Eulálio que o convívio com Balbino tenha sido importante para que não possuísse preconceito, "garanto que a convivência com Balbino fez de mim um adulto sem preconceito de cor." (BUARQUE, 2009, p. 20). E argumenta, como prova disso, a sua paixão por Matilde, uma mulata. Ainda demonstra a diferença com relação à mãe e ao pai no que diz respeito à expressão de preconceito. A mãe chega a perguntar-lhe "se Matilde não tinha cheiro de corpo"; já o pai, fazia questão de ressaltar que "só apreciava as louras e as ruivas, de preferência sardentas." (BUARQUE, 2009, p. 20).

Nessa diferenciação com o pai, destaca-se o jogo de cores, enquanto o progenitor gostava de mulheres sardentas, Eulálio apaixona-se por Matilde, que surpreendia pela "alvura dos seios" que brotava "de um colo tão moreno" e ao lado "suas coxas com a pele perfeitamente morena, sem mancha alguma." (BUARQUE, 2009, p. 158). De forma irônica, em contraste com a amante do pai - a sardenta -, Matilde apresenta-se como 
imaculada, associada à brancura (dos seios), como aquela que não possui nenhuma mancha.

No entanto, não se deve confiar plenamente nas garantias dadas pelo narrador sobre ausência de preconceito de sua parte. É importante estar alerta para a imagem de máscara contida na aparência de civilização ilustrada presente na sociedade brasileira, historicamente baseada na cultura escravocrata. Sociedade ambivalente, marcada pelo amálgama desconcertante de civilização e barbárie, ordem e desordem, como bem mostra Antonio Candido em "Dialética da malandragem". Frise-se que na sociedade brasileira, segundo Roberto Schwarz, não se pode esquecer que os "horrores da estrutura social não impossibilitavam a freqüentação extensa da vida intelectual européia." (SCHWARZ, 1997, p. 181). Como símbolo disso, o romance de Chico Buarque mostra, como relíquia da família dos Assumpção, o chicote escravocrata escondido na biblioteca, por trás da enciclopédia Larousse, símbolo da ilustração.

Na leitura do romance Memórias Póstumas de Brás Cubas, Roberto Schwarz traça o comportamento de personagens representantes da elite brasileira, como Contrim e Brás Cubas, e identifica a contradição de seus comportamentos, já que viviam às custas do trabalho escravo e, diante da sociedade, primavam em mostrar uma aparência de ilustrados, civilizados e modernos. "O indivíduo evoluído não tem escravos, não bate neles e não contrabandeia no ramo." (SCHWARZ, 1997, p. 118). Em Leite Derramado, a ironia ao comportamento da elite brasileira sobressai em meio à exposição da fachada de refinamento que recobre o porte da família do senador Assumpção. O senador apresenta-se como um lord, impecável em seu traje; a esposa, Maria Violeta, compra os seus vestidos na Europa e é freguesa dileta das costureiras francesas; a língua escolhida para se comunicar em casa é o francês. O ranço do tratamento senhorial, entretanto, permanece, como se vê, nas atitudes desabusadas do menino Eulálio com a empregada e mesmo no tom imperativo com que o narrador-personagem se dirige às pessoas de um modo geral. Significado disso, o chicote escravocrata, sobrevivente como relíquia de família, perdura, por extensão, como um símbolo da sociedade escravocrata na cultura brasileira.

Desse ângulo, a afirmação de Eulálio d'Assumpção, "garanto que a convivência com Balbino fez de mim um adulto sem preconceitos de cor", corresponde a uma falsa crença na democracia racial no Brasil, na feliz convivência entre brancos, 
negros e mestiços (FREYRE, 2006). A auto-consideração que faz Eulálio é de homem civilizado, ético e democrático. O texto de Chico Buarque, no entanto, é de fina ironia. A lupa da narrativa desmente o narrador-personagem, as atitudes que tem em relação à Matilde desacreditam as garantias dadas por ele mesmo. Eulálio é flagrado, em várias passagens, manifestando preconceito em relação ao comportamento e à cultura da esposa. Ele a reprova em sua maneira de ser, seu comportamento, suas preferências musicais, seu jeito de dançar, vestir-se, portar-se em público.

Ora, estamos, então, diante de um artifício literário bastante preparado para expor as imagens, situações e atos um tanto desconcertantes das gentes do Brasil. Tal artifício reitera Memórias Póstumas de Brás Cubas, cujo narrador, livre da censura, devido à condição de defunto, denuncia a si mesmo. Não diferente do narrador machadiano que Roberto Schwarz (1997) identificou como se estivesse no banco dos réus, o narrador buarqueano faz, de forma indireta, uma espécie de auto-julgamento. Segundo Freud, "afirmar ou negar o conteúdo é tarefa da função do julgamento intelectual." (FREUD, 2006, p. 266). A função do julgamento está relacionada, em geral, com duas espécies de decisões: afirmar ou negar. Nesse processo ocorre uma discussão sobre a representação de uma determinada realidade. $\mathrm{O}$ narrador do romance em questão, ao negar os fatos desagradáveis, atos politicamente incorretos, dá mais destaque para a existência dessa realidade, torna-a visível, presente, de modo que, diante da sua força representativa, o "não", o "nunca", o "jamais" tem o seu sentido esvaziado. Assim, em artigo sobre Leite Derramado, entende Roberto Schwarz que, o personagem da elite carioca, Eulálio d'Assumpção, está em "uma situação machadiana, em que a crítica social não se faz diretamente, mas pela auto-exposição 'involuntária' de um figurão [...] Este sem querer vai entregando os segredos de sua classe, em especial, os podres." (SCHWARZ, 2011).

Por entre a pretensiosa história do narrador acerca da genealogia e dos membros que compõem o círculo social em que convive, escorre um contradiscurso. De acordo com Freud (2006), a realidade indesejada, por vezes, só é possível vir à tona acompanhada de uma negação que a desfaz. A negativa constitui, desse ponto de vista, um modo de se alcançar um conhecimento que se encontra acobertado. No romance em questão, o estado de decadência, a perda da representatividade do nome e do status social traz a necessidade do mascaramento, do enaltecimento de si, do "esplendor ilusório" como forma de 
proteção e conservação social. Como o mentiroso nietzschiano, a voz discursiva:

serve-se das designações válidas, as palavras, para fazer o imaginário surgir como efetivo; ele diz, por exemplo, 'sou rico', quando para seu justamente 'pobre' seria a designação mais acertada. Ele abusa das convenções arbitrárias ou inversões dos nomes, inclusive. (NIETZSCHE, 2007, p. 29-30).

Assim, através de um artifício literário bastante preparado para expor as imagens, as situações e os atos um tanto desconcertantes, o texto de Chico Buarque desconstrói o discurso de um dos representantes da elite no Brasil.

\title{
THE ILLUSORY SPLENDOR IN A SPILT DISCOURSE
}

\begin{abstract}
This paper aims to analyze the language game used in the narrator's discourse in Chico Buarque's novel Spilt Milk, based on the following texts: Freud's "The negative" and Nietzsche's "On truth and lie in an extramoral sense". This reading intends to show how truth and lies, already discussed in Buarque's song-poem "Verdadeira embolada", are intertwined in this literary work. It raises a reflection on how the astuteness of word is used to expose and unmask a Brazilian hotshot from his involuntary confession.
\end{abstract}

Keywords: Spilt Milk. Chico Buarque. Illusory splendor. Nietzsche. Freud.Referências

\section{REFERÊNCIAS}

BAKHTIN, Mikhail. Problemas da poética de Dostoiévski. 5. ed. Tradução de Paulo Bezerra. Rio de Janeiro: Forense Universitária, 2010. 
BUARQUE, Chico. Leite Derramado. São Paulo: Companhia das letras, 2009.

DAMATTA, Roberto. "Teoria e prática do 'Sabe com quem está falando?'”. In: Carnavais, malandros e heróis: Para uma sociologia do dilema brasileiro. 6. ed. Rio de Janeiro: Rocco, 1997, p. 187-248.

FREYRE, Gilberto. Casa-grande e senzala. Formação da família brasileira sob o regime patriarcal. 51. ed. São Paulo: Global, 2006.

FREUD, Sigmund. A negativa. In: FREUD, S. O ego e o id e outros trabalhos (1923-1925) V. XIX. Tradução de Jayme Salomão. Rio de Janeiro: Imago, 2006, p. 263-269.

NIETZSCHE, Friedrich Wilheln. Sobre verdade e mentira no sentido extra-moral. In: NIETZSCHE, F.W. Sobre verdade e mentira. Organização e tradução de Fernando de Morais Barros. São Paulo: Hedra, 2007, p. 25-52.

SCHWARZ, Roberto. Leite Derramado. Brincalhão, mas não ingênuo. In: Folha de S.Paulo. 04/04/09. Disponível em: http://criticadialetica.blogspot.com/leite-derramado.html. Acesso em: 15/10/11.

SCHWARZ, Roberto. Um mestre na periferia do capitalismo. 3. ed. São Paulo: 34, 1997.

Recebido em: 03/08/2015

Aceito em: 09/06/2016 